\title{
Surgical results of the Carotid Occlusion Surgery Study
}

\author{
Clinical article
}

\author{
Robert L. Grubb JR., M.D., ${ }^{1,2}$ William J. Powers, M.D., ${ }^{4}$ William R. Clarke, Ph.D., ${ }^{5}$ \\ Tom O. Videen, Ph.D., ${ }^{2,3}$ Harold P. Adams Jr., M.D., ${ }^{6}$ and Colin P. Derdeyn, M.D., ${ }^{1-3}$ \\ for the Carotid Occlusion Surgery Study Investigators
}

\begin{abstract}
Departments of ${ }^{1}$ Neurological Surgery, ${ }^{2}$ Radiology, and ${ }^{3}$ Neurology, Washington University School of Medicine in St. Louis, Missouri; ${ }^{4}$ Department of Neurology, University of North Carolina School of Medicine, Chapel Hill, North Carolina; ${ }^{5}$ Clinical Trials Statistics and Data Management Center, University of Iowa College of Public Health; and ${ }^{6}$ Department of Neurology, University of Iowa Carver School of Medicine, Iowa City, Iowa
\end{abstract}

Object. The Carotid Occlusion Surgery Study (COSS) was conducted to determine if superficial temporal artery-middle cerebral artery (STA-MCA) bypass, when added to the best medical therapy, would reduce subsequent ipsilateral stroke in patients with complete internal carotid artery (ICA) occlusion and an elevated oxygen extraction fraction $(\mathrm{OEF})$ in the cerebral hemisphere distal to the occlusion. A recent publication documented the methodology of the COSS in detail and briefly outlined the major findings of the trial. The surgical results of the COSS are described in detail in this report.

Methods. The COSS was a prospective, parallel-group, 1:1 randomized, open-label, blinded-adjudication treatment trial. Participants, who had angiographically demonstrated complete occlusion of the ICA causing either a transient ischemic attack or ischemic stroke within 120 days and hemodynamic cerebral ischemia indicated by an increased OEF measured by PET, were randomized to either surgical or medical treatment. One hundred ninety-five patients were randomized: 97 to the surgical group and 98 to the medical group. The surgical patients underwent an STA-MCA cortical branch anastomosis.

Results. In the intention-to-treat analysis, the 2-year rates for the primary end point were $21 \%$ for the surgical group and $22.7 \%$ for the medical group $(\mathrm{p}=0.78$, log-rank test). Fourteen $(15 \%)$ of the 93 patients who had undergone an arterial bypass had a primary end point ipsilateral hemispheric stroke in the 30-day postoperative period, 12 within 2 days after surgery. The STA-MCA arterial bypass patency rate was $98 \%$ at the 30 -day postoperative visit and $96 \%$ at the last follow-up examination. The STA-MCA arterial bypass markedly improved, although it did not normalize, the level of elevated OEF in the symptomatic cerebral hemisphere. Five surgically treated and 1 nonsurgically treated patients in the surgical group had a primary end point ipsilateral hemispheric stroke after the 30-day postoperative period. No baseline characteristics or intraoperative variables revealed those who would experience a procedure-related stroke.

Conclusions. Despite excellent bypass graft patency and improved cerebral hemodynamics, STA-MCA anastomosis did not provide an overall benefit regarding ipsilateral 2 -year stroke recurrence, mainly because of a much better than expected stroke recurrence rate $(22.7 \%)$ in the medical group, but also because of a significant postoperative stroke rate $(15 \%)$. Clinical trial registration no.: NCT00029146.

(http://thejns.org/doi/abs/10.3171/2012.9.JNS12551)

KEY WoRDS $\bullet \quad$ symptomatic occluded internal carotid artery
superficial temporal artery-middle cerebral artery anastomosis $\bullet$
impaired cerebral hemodynamics $\bullet$ positron emission tomography
oxygen extraction fraction $\bullet \quad$ randomized trial $\bullet \quad$ vascular disorders

$\mathrm{C}$

OMPLETE occlusion of the ICA by atherosclerotic disease causes approximately $15 \%-25 \%$ of ischemic strokes in the carotid artery distribution..$^{22,26,37}$

Abbreviations used in the paper: COSS = Carotid Occlusion Surgery Study; EC-IC = extracranial-intracranial; EC-IC bypass trial = The International Study of Extracranial-to-Intracranial Arterial Anastomosis; ICA = internal carotid artery; IRB = institutional review board; MCA = middle cerebral artery; NINDS = National Institute of Neurological Disorders and Stroke; OA = occipital artery; OA-MCA = occipital artery-middle cerebral artery; $\mathrm{OEF}=$ oxygen extraction fraction; $\mathrm{POD}=$ postoperative day; $\mathrm{STA}-\mathrm{MCA}=$ superficial temporal artery-middle cerebral artery; TIA = transient ischemic attack.
Patients treated with medical therapy have a 7\%-10\% risk of recurrent stroke per year for any stroke and a 5\%-8\% risk per year for ipsilateral ischemic stroke during the first 2 years after ICA occlusion. ${ }^{17,18,20,21}$ Internal carotid artery occlusion causes an estimated 61,000 firstever strokes per year in the US, ${ }^{1,6,14,22,26,37,39}$ an incidence more than twice the annual occurrence of ruptured intracranial aneurysms. ${ }^{5}$ Superficial temporal artery-middle cerebral artery anastomosis was developed to improve hemodynamics distal to an occluded artery. ${ }^{11,38,41}$ The International Study of Extracranial-to-Intracranial Arterial Anastomosis (EC-IC bypass trial) tested the usefulness 
of STA-MCA bypass surgery as a prophylaxis against stroke. ${ }^{13}$ STA-MCA bypass was not effective in preventing subsequent stroke as compared with the best medical therapy in any group of patients, including the 808 patients with symptomatic complete occlusion of the ICA. Based on results of this trial, EC-IC arterial bypass was generally abandoned as a treatment for symptomatic complete ICA occlusion. After the trial, several groups criticized the results on multiple grounds, ${ }^{2,8,35}$ including the inability to identify and separately analyze a subgroup of patients with impaired cerebral hemodynamics due to occlusive cerebrovascular disease in whom surgical revascularization might be more beneficial. ${ }^{8}$

Since then, advances in neuroimaging have made it possible to determine the hemodynamic effects of ICA occlusion in individual patients. $9,10,16,20,24,40$ The strongest evidence for an association between cerebral hemodynamic impairment and stroke was provided by the St. Louis Carotid Occlusion Study (STLCOS). ${ }^{16}$ In this blinded prospective study, investigators found that severe hemodynamic failure, manifested by an elevated OEF in the cerebral hemisphere distal to complete ICA occlusion, was an independent predictor of subsequent stroke in symptomatic medically treated patients. The STA-MCA arterial bypass surgery has been shown to improve cerebral hemodynamics distal to an occluded ICA.4,15,17,29,28,33

The Carotid Occlusion Surgery Study (COSS) was a prospective, parallel-group, 1:1 randomized, open-label, blinded-adjudication treatment trial designed to test the hypothesis that STA-MCA anastomosis, when combined with the best medical therapy, could reduce by $40 \%$ the subsequent occurrence of ipsilateral ischemic stroke at 2 years in patients with recent symptomatic ICA occlusion and ipsilateral increased OEF as measured by PET. The trial design and analysis as well as primary results have already been reported. ${ }^{27}$ The primary end points in the surgical group were 1) all stroke and death from surgery through 30 days postoperatively plus 2) ipsilateral hemispheric ischemic stroke within 2 years of randomization. The primary end points in the nonsurgical group were 1) all stroke and death from randomization through 30 days plus 2) ipsilateral hemispheric ischemic stroke within 2 years of randomization. All primary end points were ipsilateral ischemic strokes. Based on an intent-to-treat analysis, 2-year rates for ipsilateral ischemic stroke were $21.0 \%$ (20 events, 95\% CI 12.8\%-29.2\%) for the 97 participants in the surgical group and $22.7 \%$ (20 events, $95 \%$ CI $13.9 \%-31.6 \%$ ) for the 98 patients in the nonsurgical group $(\mathrm{p}=0.78$, $\mathrm{z}$-test; difference $=1.7 \% ; 95 \% \mathrm{CI}-10.4 \%$ to $13.8 \%$ ).

The initial report of results for the COSS trial ${ }^{27}$ had only a brief description of the major findings, which are reviewed in the current article. In addition, we include a large amount of unpublished data about the STA-MCA bypass procedures done in this trial, which we believe should be widely available to vascular neurosurgeons. Reports of the original EC-IC bypass trial ${ }^{3,13}$ contained few details about the 652 STA-MCA bypasses performed in that study. These data are no longer available, which is a major loss for vascular neurosurgery.

\section{Methods}

\section{Informed Consent}

Study participants provided written informed consent according to local IRB regulations and study protocol requirements (COSS Clinical Coordinating Center IRB approval: Washington University in St. Louis Human Research Protection Office \#01-370 and University of North Carolina IRB Approval \#307-1020; US FDA IND \#62,657). This clinical trial (no. NCT00029146) was registered with ClinicalTrials.gov (http://clinicaltrials.gov).

\section{Surgical Procedure}

The EC-IC arterial bypass procedure used in the COSS trial was a standard STA-MCA cortical branch anastomosis. ${ }^{12,25,30,41}$ If the STA was not suitable for anastomosis to the MCA, the OA could be used in place of the STA. All surgical patients were placed on 81 or $325 \mathrm{mg}$ of aspirin daily prior to the bypass procedure. All other perioperative issues, such as anticonvulsants, antibiotics, choice of anesthetic agents, intraoperative hemodynamic monitoring, and perioperative fluid loading, were left to the discretion of the operating surgeon. The STA-MCA cortical branch anastomosis was done using the best STA branch and the best MCA cortical branch. Only one anastomosis was done in each patient. Patients with an "unsuitable" STA (diameter $<1 \mathrm{~mm}$ ) were excluded from the study. Details of the surgical technique used for the STAMCA anastomosis, such as the use of running or interrupted 10-0 Prolene or nylon sutures, a straight or elliptical incision in the MCA cortical branch, and preparation of the STA graft, were left to the discretion of the operating surgeon. During and immediately following the surgical procedure, data concerning anesthesia techniques, intraoperative blood pressures, cerebral monitoring, and technical aspects of the bypass procedure were recorded and saved for analysis. After surgery, all patients were left on 81 or $325 \mathrm{mg}$ of aspirin for at least 30 days. Thereafter, when deemed appropriate by the neurosurgeon, patients were returned to the antithrombotic treatment preferred by their physicians. Intraoperative assessment of STAMCA bypass patency was performed using Doppler ultrasound examination and/or cerebral angiography. The first follow-up visit was 30-35 days after randomization. All surgical participants underwent repeat PET scanning 30-60 days postoperatively. Subsequent follow-up visits occurred at 3-month intervals after randomization until 24 months or the end of the trial. Doppler ultrasound examination was used to determine postoperative STAMCA bypass patency at follow-up visits.

\section{Surgical Certification}

Surgeons were certified for the study 1) by attending an initial training workshop in St. Louis where videotaped instruction was viewed and surgical practice of microvascular anastomosis was performed on frozen cadaver heads and live rat carotid arteries, or 2) by demonstrating at least $80 \%$ bypass graft patency and $\leq 10 \%$ incidence of stroke and death at 1 month in at least 10 consecutive STA-MCA bypass surgeries. Surgeons with fewer than 10 STA-MCA bypass cases available for re- 
view received provisional certification to perform the STA-MCA bypass in an enrolled patient under the supervision of the principal neurosurgical investigator for the trial or a designated neurosurgeon with extensive STAMCA bypass experience.

\section{Further Cerebrovascular Procedures}

Both the nonsurgical and surgical patients were prohibited from undergoing any additional surgical procedures after the STA-MCA arterial bypass that might alter cerebral hemodynamics or affect stroke risk, except for a carotid endarterectomy performed for the development of symptomatic contralateral stenosis of the ICA.

\section{Statistical Analysis}

Categorical variables are displayed as counts and rates, and continuous variables are displayed as means \pm standard deviations. Univariate analyses were used to compare baseline values and intraoperative variables between those who had a stroke within 2 days of surgery and those who did not. We compared the 2 groups using generalized Fisher exact tests for categorical variables, t-tests for continuous variables that were approximately normally distributed, and Wilcoxon rank-sum tests for variables that were not normally distributed (noted in tables). Even though there were a large number of such comparisons, we did not adjust $p$ values for the multiplicity. For the comparison of 2-year outcomes between surgeons who were department or division chairs and those who were not, Kaplan-Meier methods were used to describe the distribution of time to primary event for each group. The log-rank test was used to compare the 2 distributions.

\section{Results}

Thirty different surgeons (Appendix) performed 92 STA-MCA bypasses and 1 OA-MCA bypass at a median of 6 days (interquartile range 1-13 days) after randomization to the surgical group. Four participants randomized to the surgical group did not undergo surgery. No strokes occurred during the time between randomization and surgery. The bypass patency rate was excellent: $98 \%$ (88 of 90 patients with patency data) at the 30-day postoperative visit. One patient died in the postoperative period, and graft patency data were not recorded in 2 other patients at the 30-day follow-up visit. At the last follow-up visit during which STA-MCA arterial bypass patency was assessed (mean $605 \pm 270$ days, range 28-1596 days), the graft patency rate was $96 \%$ (86 of 90 patients with patency data). The mean OEF ratio in the surgical group improved from $1.258 \pm 0.14$ at baseline (93 patients) to $1.109 \pm 0.101$ at the 30 - to 60 -day postoperative repeat PET (87 patients). Comparing the 87 patients who had both a preoperative and a postoperative PET scan, the mean OEF ratio improved from $1.254 \pm 0.135$ to 1.109 \pm 0.101 ( $p<0.0001)$. In a previous study, the upper limit of the OEF ratio calculated using similar methods in 18 normal patients was $1.062 .{ }^{16}$ Twenty-nine percent (25 of 87) of the postoperative PET scans in the COSS had an OEF ratio within the normal range.

Fourteen (15\%) of the 93 patients who underwent an arterial bypass had a primary end point ipsilateral hemi- spheric stroke in the 30-day postoperative period. Twelve of the 14 postoperative ipsilateral hemispheric strokes occurred within the first 2 days following surgery; the other 2 cases occurred 5 and 15 days after surgery. The occurrence of 2 strokes more than 2 days after surgery, but within 30 days, was a pattern identical to that observed in the nonsurgical group of 98 patients, which had 2 ipsilateral strokes within 30 days of randomization.

Of the 14 strokes occurring within the 30-day postoperative period, 2 were disabling at the last follow-up (Barthel Index < 12) and 1 was fatal. The patient who died in the postoperative period had 2 ipsilateral strokes on the day of surgery, had a vertebrobasilar artery distribution stroke on POD 1, and died on POD 4. The bypass in this patient was believed to be patent during the surgical procedure. A second patient had a postoperative ipsilateral stroke on the day of surgery. This bypass was also thought to be patent during the procedure, but the graft was occluded at the 30-day follow-up visit. In a third patient, the bypass was not patent at the completion of surgery and an ipsilateral stroke occurred on POD 1. Thus, at the 30-day follow-up visit, the STA-MCA bypass was patent in 11 of the 14 patients who had an ipsilateral hemispheric stroke 30 days postoperatively. The bypass was patent at the last follow-up in the 2 patients who had had a disabling ipsilateral hemispheric stroke postoperatively. In 2 patients who had an ipsilateral hemispheric stroke in the 30-day postoperative period, other serious adverse events occurred during this time (Table 1). One of them also had an episode of hypoglycemia on POD 2 , a deep venous thrombosis on POD 6, an episode of atrial fibrillation/flutter on POD 9, a pulmonary embolus on POD 9, and a nonfatal cardiac tamponade on POD 14. The second patient had a small asymptomatic subdural hematoma and significant anemia on POD 3.

Twelve additional patients who did not have a 30day postoperative stroke had serious adverse events in the postoperative period (Table 1). Among these events were TIAs that occurred in 4 patients on PODs 1, 7, 8, and 9, respectively. Three of these TIAs were reported as ipsilateral hemispheric strokes by the clinical sites but were later adjudicated as TIAs. Two of the 12 patients had a subdural hematoma (PODs 21 and 26). The subdural hematoma found on POD 26 required surgical drainage. The patient in this case also had a postoperative ipsilateral hemispheric stroke on POD 52. Other events in these 12 patients included a significant myocardial infarction on POD 0 , severe respiratory distress on POD 0 , a wound infection, an episode of severe hypotension, and a seizure in 2 patients.

The surgical certification method and the 30-day postoperative stroke rate among the 30 surgeons who performed surgeries in the COSS are outlined in Table 2. Fifteen of the 30 surgeons in the trial were certified by attending the initial training workshop. They performed 64 STA-MCA arterial bypasses in the trial, with 11 postoperative ipsilateral strokes (17\%). Thirteen surgeons were certified by submitting data on 10 or more consecutive STA-MCA arterial bypasses that met the criteria listed above. In the trial they performed 24 STA-MCA arterial bypasses, with 3 postoperative ipsilateral strokes (12\%). 
TABLE 1: Thirty-day postoperative nonstroke serious adverse events*

\begin{tabular}{lcc}
\hline \multicolumn{1}{c}{ Event } & No. of Events & POD \\
\hline TIA & 4 & $1,7,8,9$ \\
subdural hematoma & 3 & $3,21,26$ \\
wound infection & 1 & 25 \\
myocardial infarction & 1 & 0 \\
respiratory distress & 1 & 0 \\
seizure & 2 & 2,3 \\
DVT & 1 & 6 \\
pulmonary embolus & 1 & 9 \\
atrial fibrillation/flutter & 1 & 9 \\
cardiac tamponade & 1 & 14 \\
severe hypotension & 1 & 19 \\
hypoglycemia & 1 & 2 \\
severe anemia & 1 & 3 \\
\hline
\end{tabular}

* DVT = deep venous thrombosis.

Only 2 surgeons in the trial had provisional certification, and they performed 5 STA-MCA arterial bypasses, with no perioperative strokes. Thus, there was no significant difference in the method of surgical certification for the trial and the incidence of 30-day postoperative stroke ( $p$ $=0.91)$ or any (total) stroke $(\mathrm{p}=0.84)$.

Seventeen of the 30 surgeons in the trial provided self-reported data for 292 EC-IC arterial bypasses for the grant submission to the National Institutes of Health for funds to conduct the study. Twenty-seven patients $(9.2 \%)$ in these 292 bypasses had a stroke or died in the 30-day postoperative period. The same 17 surgeons in the COSS trial performed 72 STA-MCA arterial bypasses, with 8 patients $(11.1 \%)$ having an ipsilateral stroke in the postoperative period, which was not significantly different from their pre-COSS experience $(\mathrm{p}=0.655)$.

Twenty of the surgeons submitted data either for the initial grant submission or as part of the certification process documenting at least $80 \%$ graft patency in at least 10 consecutive EC-IC procedures, and thus they would have qualified for participation in the original EC-IC bypass trial. ${ }^{13}$ The 30 -day rate for postoperative ipsilateral stroke for these 20 surgeons (7 [13.2\%] of 53 surgeries) was not significantly different from that among the other 10 surgeons (7 [17.5\%] of 40 surgeries; $p=0.77$ ), nor was the rate of total stroke different (10 [18.9\%] of 53 surgeries vs $9[22.5 \%]$ of 40 surgeries, $p=0.80$ ). Fifteen of the participating surgeons were department or division chairs.

\section{TABLE 2: Surgical certification and 30-day postoperative stroke} rate

\begin{tabular}{lcc}
\hline \multicolumn{1}{c}{ Method of Certification } & $\begin{array}{c}\text { No. of } \\
\text { Surgeons }\end{array}$ & $\begin{array}{c}\text { No. of Postop } \\
\text { Strokes (\%) }\end{array}$ \\
\hline initial workshop attendance & 15 & $11 / 64(17)$ \\
submission 10 consecutive cases & 13 & $3 / 24(12)$ \\
provisional certification & 2 & $0 / 5(0)$ \\
\hline
\end{tabular}

Their 30-day rate of postoperative ipsilateral stroke (6 [13.6\%] of 44 surgeries) was not significantly different from the other 15 surgeons ( 8 [16.3\%] of 49 surgeries; $p$ $=0.77$ ), nor was the Kaplan-Meier estimated rate of total stroke at 2 years different $(9$ [20.4\%] of 44 surgeries vs 10 [20.4\%] of 49 surgeries, $p=0.94)$. Since the postoperative stroke rate negated any net benefit of the bypass surgery, we sought to identify factors that would predict postoperative stroke occurrence. We performed these analyses for the 12 strokes that occurred within 2 days of surgery, since these were the strokes most likely to be directly related to surgery. The additional 2 strokes within 30 days of surgery mirrored the number that occurred in the nonsurgical group within 30 days of randomization. Even though this type of analysis is hazardous because of the increase in the false-positive rate given the large number of variables analyzed, we found no baseline or intraoperative variables, including the duration of the MCA cortical branch occlusion and the degree of OEF elevation in the symptomatic cerebral hemisphere, that were different at the $p \leq 0.05$ level between those who experienced a stroke within 2 days of surgery and those who did not (Tables 3-5).

Five surgically treated patients had a primary end point ipsilateral hemispheric stroke after the 30-day postoperative period. (One nonsurgically treated patient randomized to surgery had a primary end point ipsilateral hemispheric stroke within the 2-year follow-up period.) In all 5 of these patients, the STA-MCA bypass was documented as patent following the procedure and before the stroke. In 4 of these patients, the bypass was documented as still patent after the stroke. No information was recorded about bypass patency following stroke in the other patient. Thus, among the 19 patients who had a primary end point ipsilateral hemispheric stroke after surgery, the bypass was documented as patent in 15 of the patients after the stroke. Two additional patients who underwent successful STA-MCA bypasses had strokes in the cerebral hemisphere contralateral to the symptomatic occluded carotid artery. Both of these patients had $<50 \%$ stenosis of the contralateral carotid artery at the time of randomization, and their bypasses were patent at the last follow-up. In 1 patient, the stroke occurred on POD 556, and the other patient had contralateral hemispheric strokes on PODs 279 and 608.

Eliminating from the analysis the 12 surgical patients who had strokes within 2 days of surgery while retaining the 2 who had strokes between 2 and 30 days (because of the same number occurring in the nonsurgical group within 30 days of randomization), we calculated the rate of recurrent stroke for the remaining 81 patients in the surgical group as $9.0 \%$ compared with $22.7 \%$ in the nonsurgical group.

\section{Discussion}

Prior to the start of the trial, there was concern that problems might be encountered with STA-MCA bypass graft patency rates during the study, as most vascular neurosurgeons had not performed the procedure in patients with cerebral ischemia after the results of the ECIC bypass trial were published in $1985 .{ }^{13}$ However, the 
TABLE 3: Comparison of baseline characteristics between patients who did and did not experience stroke within 2 days after bypass surgery*

\begin{tabular}{|c|c|c|c|c|}
\hline \multirow[b]{2}{*}{ Characteristic } & \multirow{2}{*}{$\begin{array}{c}\text { Total } \\
\text { No. }\end{array}$} & \multicolumn{2}{|c|}{ Postop Stroke w/in 2 Days } & \multirow[b]{2}{*}{ p Value } \\
\hline & & No & Yes & \\
\hline no. of patients & 93 & 81 & 12 & \\
\hline mean age in yrs & & $57.8 \pm 9.3$ & $61.1 \pm 7.6$ & $0.245 \dagger$ \\
\hline sex & & & & $0.999 \ddagger$ \\
\hline M & 66 & 57 & 9 & \\
\hline $\mathrm{F}$ & 27 & 24 & 3 & \\
\hline race & & & & $0.599 \ddagger$ \\
\hline white & 84 & 72 & 12 & \\
\hline other & 9 & 9 & 0 & \\
\hline hypertension & & & & $0.696 \ddagger$ \\
\hline no & 18 & 15 & 3 & \\
\hline yes & 75 & 66 & 9 & \\
\hline atrial fibrillation & & & & $0.999 \ddagger$ \\
\hline no & 92 & 80 & 12 & \\
\hline yes & 1 & 1 & 0 & \\
\hline hyperlipidemia & & & & $0.999 \ddagger$ \\
\hline no & 16 & 14 & 2 & \\
\hline yes & 77 & 67 & 10 & \\
\hline diabetes mellitus & & & & $0.717 \ddagger$ \\
\hline no & 73 & 64 & 9 & \\
\hline yes & 20 & 17 & 3 & \\
\hline cigarette smoking & & & & $0.329 \ddagger$ \\
\hline never & 7 & 6 & 1 & \\
\hline former & 54 & 45 & 9 & \\
\hline current & 32 & 30 & 2 & \\
\hline previous Ml & & & & $0.117 \ddagger$ \\
\hline no & 83 & 74 & 9 & \\
\hline yes & 10 & 7 & 3 & \\
\hline previous stroke & & & & $0.138 \ddagger$ \\
\hline no & 48 & 44 & 4 & \\
\hline yes & 43 & 36 & 7 & \\
\hline unknown & 2 & 1 & 1 & \\
\hline study entry event type & & & & $0.130 \ddagger$ \\
\hline TIA & 42 & 34 & 8 & \\
\hline stroke & 51 & 47 & 4 & \\
\hline study entry event side & & & & $0.348 \ddagger$ \\
\hline $\mathrm{rt}$ & 54 & 49 & 5 & \\
\hline It & 39 & 32 & 7 & \\
\hline $\begin{array}{l}\text { mean no. of days from } \\
\text { study entry event to } \\
\text { randomization }\end{array}$ & & $73.8 \pm 38.5$ & $53.1 \pm 27.5$ & $0.093 \S$ \\
\hline $\begin{array}{l}\text { mean no. of days } \\
\text { from randomization } \\
\text { to surgery }\end{array}$ & & $10.7 \pm 13.3$ & $7.3 \pm 6.7$ & $0.735 \S$ \\
\hline
\end{tabular}

(continued)
TABLE 3: Comparison of baseline characteristics between patients who did and did not experience stroke within 2 days after bypass surgery* (continued)

\begin{tabular}{|c|c|c|c|c|}
\hline \multirow[b]{2}{*}{ Characteristic } & \multirow{2}{*}{$\begin{array}{l}\text { Total } \\
\text { No. }\end{array}$} & \multicolumn{2}{|c|}{ Postop Stroke w/in 2 Days } & \multirow[b]{2}{*}{ p Value } \\
\hline & & No & Yes & \\
\hline $\begin{array}{l}\% \text { contralat carotid ste- } \\
\text { nosis }\end{array}$ & & & & $0.999 \ddagger$ \\
\hline$<50$ & 75 & 65 & 10 & \\
\hline $50-69$ & 11 & 10 & 1 & \\
\hline$\geq 70$ & 7 & 6 & 1 & \\
\hline $\begin{array}{l}\text { mean modified Barthel } \\
\text { Index }\end{array}$ & & $19.2 \pm 1.9$ & $20.0 \pm 0.0$ & $0.113 \S$ \\
\hline mean mRS score & & $1.4 \pm 1.1$ & $1.1 \pm 0.9$ & $0.375 \S$ \\
\hline mean NIHSS & & $1.8 \pm 2.2$ & $1.4 \pm 1.9$ & $0.642 \S$ \\
\hline mean summary SS-QoL & & $3.7 \pm 0.9$ & $4.1 \pm 0.8$ & $0.146 \dagger$ \\
\hline $\begin{array}{l}\text { mean systolic BP in } \\
\mathrm{mm} \mathrm{Hg}\end{array}$ & & $132.3 \pm 14.8$ & $132.3 \pm 18.2$ & $0.948 \dagger$ \\
\hline $\begin{array}{l}\text { mean diastolic BP in } \\
\qquad \mathrm{mm} \mathrm{Hg}\end{array}$ & & $77.0 \pm 10.4$ & $72.4 \pm 10.8$ & $0.163 \dagger$ \\
\hline mean PET OEF ratio & & $1.25 \pm 0.13$ & $1.29 \pm 0.18$ & $0.381 \dagger$ \\
\hline $\begin{array}{l}\text { no. of angiographic col- } \\
\text { laterals }\end{array}$ & & & & $0.475 \ddagger$ \\
\hline 0 & 10 & 9 & 1 & \\
\hline 1 & 34 & 31 & 3 & \\
\hline 2 & 42 & 36 & 6 & \\
\hline 3 & 7 & 5 & 2 & \\
\hline mean hematocrit & & $41.2 \pm 4.8$ & $38.8 \pm 3.2$ & $0.099 \dagger$ \\
\hline
\end{tabular}

* $\mathrm{BP}=$ blood pressure; $\mathrm{Ml}=$ myocardial infarction; $\mathrm{mRS}=$ modified Rankin Scale; NIHSS = National Institutes of Health Stroke Scale; SSQoL = Stroke-Specific Quality of Life.

t t-Test.

$\ddagger$ Fisher exact test.

$\S$ Wilcoxon rank-sum test.

STA-MCA arterial graft patency rates of $96 \%-98 \%$ in the COSS trial were similar to those obtained in the ECIC bypass trial and other reported patient series. In the EC-IC bypass trial, repeat cerebral angiography was performed at a median of 32 days postoperatively in $92 \%$ of the 652 patients who had undergone an STA-MCA bypass procedure, and $96 \%$ of these patients had a patent STAMCA anastomosis..$^{13}$ In a report of 415 STA-MCA anastomoses performed at a single institution over an 8-year period, a graft patency rate of $99 \%$ was achieved..$^{36} \mathrm{Ce}$ rebral angiography was used to assess graft patency in the first 260 patients, and a Doppler velocity flow probe examination was performed in the remaining patients in that study. The same investigators confirmed a $96 \%$ graft patency rate on cerebral angiography in a separate analysis of 163 of these patients who had undergone an STAMCA anastomosis for cerebral ischemic symptoms due to complete ICA occlusion. ${ }^{19}$ Other case series of STAMCA bypasses have documented graft patency rates of 90\%-96\%.7,23,32,34,42

A 1978 literature review of multiple case series revealed an average permanent neurological morbidity rate 
R. L. Grubb Jr. et al.

TABLE 4: Comparison of intraoperative data between patients who did and did not experience stroke within 2 days after bypass surgery*

\begin{tabular}{|c|c|c|c|c|}
\hline \multirow{2}{*}{ Variable } & \multirow{2}{*}{$\begin{array}{c}\text { No } \\
\text { Stroke }\end{array}$} & \multicolumn{3}{|c|}{ Total } \\
\hline & & Stroke & No. & $p$ Value \\
\hline \multicolumn{5}{|l|}{ anesthesia } \\
\hline nitrous oxide & & & & 0.357 \\
\hline no & 48 & 9 & 57 & \\
\hline yes & 33 & 3 & 36 & \\
\hline halothane & & & & 0.999 \\
\hline no & 78 & 12 & 90 & \\
\hline yes & 3 & 0 & 3 & \\
\hline enflurane & & & & 0.999 \\
\hline no & 80 & 12 & 92 & \\
\hline yes & 1 & 0 & 1 & \\
\hline isoflurane & & & & 0.999 \\
\hline no & 49 & 7 & 56 & \\
\hline yes & 32 & 5 & 37 & \\
\hline narcotic & & & & 0.651 \\
\hline no & 10 & 2 & 12 & \\
\hline yes & 71 & 10 & 81 & \\
\hline relaxant & & & & 0.382 \\
\hline no & 11 & 3 & 14 & \\
\hline yes & 70 & 9 & 79 & \\
\hline barbiturates & & & & 0.999 \\
\hline no & 53 & 8 & 61 & \\
\hline yes & 28 & 4 & 32 & \\
\hline propofol & & & & 0.498 \\
\hline no & 35 & 2 & 37 & \\
\hline yes & 56 & 10 & 66 & \\
\hline other general anesthesia & & & & 0.999 \\
\hline no & 28 & 4 & 32 & \\
\hline yes & 53 & 8 & 61 & \\
\hline local anesthesia & & & & 0.999 \\
\hline no & 67 & 10 & 77 & \\
\hline yes & 13 & 2 & 15 & \\
\hline side of surgery & & & & 0.348 \\
\hline $\mathrm{rt}$ & 49 & 5 & 54 & \\
\hline It & 32 & 7 & 39 & \\
\hline heparin during MCA occlusion & & & & 0.403 \\
\hline no & 69 & 9 & 78 & \\
\hline yes & 12 & 3 & 15 & \\
\hline cerebral monitoring & & & & 0.504 \\
\hline no & 49 & 6 & 55 & \\
\hline yes & 32 & 6 & 38 & \\
\hline EEG & & & & 0.295 \\
\hline no & 1 & 1 & 2 & \\
\hline yes & 31 & 5 & 36 & \\
\hline
\end{tabular}

(continued)
TABLE 4: Comparison of intraoperative data between patients who did and did not experience stroke within 2 days after bypass surgery* (continued)

\begin{tabular}{|c|c|c|c|c|}
\hline & No & & Total & \\
\hline Variable & Stroke & Stroke & No. & $\mathrm{p}$ Value \\
\hline change during MCA occlusion & & & & 0.999 \\
\hline no & 28 & 5 & 33 & \\
\hline yes & 3 & 0 & 3 & \\
\hline evoked potentials & & & & 0.999 \\
\hline no & 18 & 3 & 21 & \\
\hline yes & 14 & 3 & 17 & \\
\hline change during MCA occlusion & & & & 0.999 \\
\hline no & 13 & 3 & 16 & \\
\hline yes & 1 & 0 & 1 & \\
\hline anastomosis & & & & \\
\hline interrupted & & & & 0.282 \\
\hline no & 21 & 1 & 22 & \\
\hline yes & 60 & 11 & 71 & \\
\hline running & & & & 0.202 \\
\hline no & 67 & 12 & 79 & \\
\hline yes & 14 & 0 & 14 & \\
\hline interrupted \& running & & & & 0.999 \\
\hline yes & 70 & 11 & 81 & \\
\hline no & 11 & 1 & 12 & \\
\hline suture type & & & & 0.999 \\
\hline nylon & 54 & 8 & 62 & \\
\hline Prolene & 27 & 4 & 31 & \\
\hline suture size & & & & 0.999 \\
\hline $9-0$ & 21 & 3 & 24 & \\
\hline $10-0$ & 60 & 9 & 69 & \\
\hline intraop bypass graft & & & & 0.566 \\
\hline Doppler & 58 & 8 & 66 & \\
\hline angiography & 19 & 4 & 23 & \\
\hline other & 1 & 0 & 1 & \\
\hline anastomosis patent in $\mathrm{OR}$ & & & & 0.133 \\
\hline no & 0 & 1 & 1 & \\
\hline yes & 76 & 13 & 89 & \\
\hline no data & 3 & & 3 & \\
\hline
\end{tabular}

* EEG = electroencephalography; OR = operating room.

$\dagger$ Fisher exact test.

of $2.4 \%$ and an average operative mortality rate of $4.3 \%$ among 376 STA-MCA bypass procedures. ${ }^{32}$ There was a $13.6 \%$ rate of "other morbidity" in these patients. Other series from the same era of STA-MCA bypass surgeries with 100-415 patients demonstrated perioperative stroke rates of $2 \%-3.6 \%$ and perioperative mortality rates of $1.2 \%-3 \%{ }^{7,31,42}$ A perioperative mortality rate of $2.1 \%$, a permanent neurological impairment rate of $6.4 \%$, and a morbidity rate of $25.5 \%$ were found in a more recent series of 47 patients undergoing STA-MCA bypass for cerebral ischemia symptoms, ${ }^{34}$ whereas no operative mor- 
TABLE 5: Comparison of intraoperative data between patients with or without stroke within 2 days after bypass surgery

\begin{tabular}{|c|c|c|c|c|c|c|}
\hline Variable & No. & Mean & SD & Min & Max & $p$ Value* \\
\hline average systolic BP during surgery $(\mathrm{mm} \mathrm{Hg})$ & & & & & & 0.264 \\
\hline no stroke & 81 & 132.8 & 17.8 & 98 & 199 & \\
\hline stroke & 12 & 138.9 & 15.3 & 118 & 160 & \\
\hline average diastolic BP during surgery $(\mathrm{mm} \mathrm{Hg})$ & & & & & & 0.864 \\
\hline no stroke & 81 & 66.3 & 9.7 & 40 & 90 & \\
\hline stroke & 12 & 65.8 & 9.2 & 52 & 80 & \\
\hline lowest systolic BP during surgery $(\mathrm{mm} \mathrm{Hg})$ & & & & & & 0.064 \\
\hline no stroke & 81 & 102.1 & 18.3 & 68 & 177 & \\
\hline stroke & 12 & 112.6 & 15.8 & 95 & 145 & \\
\hline lowest diastolic BP during surgery $(\mathrm{mm} \mathrm{Hg})$ & & & & & & 0.1186 \\
\hline no stroke & 81 & 54.3 & 11.0 & 30 & 98 & \\
\hline stroke & 12 & 58.8 & 9.7 & 40 & 78 & \\
\hline duration of lowest BP during surgery (min) & & & & & & 0.807 \\
\hline no stroke & 79 & 8.3 & 9.9 & 0 & 54 & \\
\hline stroke & 12 & 7.6 & 5.6 & 1 & 20 & \\
\hline duration of MCA occlusion (min) & & & & & & 0.182 \\
\hline no stroke & 78 & 45.4 & 24.2 & 15 & 123 & \\
\hline stroke & 11 & 55.9 & 25.3 & 26 & 99 & \\
\hline average systolic BP during MCA occlusion ( $\mathrm{mm} \mathrm{Hg}$ ) & & & & & & 0.572 \\
\hline no stroke & 78 & 136.2 & 20.9 & 95 & 190 & \\
\hline stroke & 11 & 140 & 20.7 & 106 & 175 & \\
\hline average diastolic BP during MCA occlusion $(\mathrm{mm} \mathrm{Hg})$ & & & & & & 0.561 \\
\hline no stroke & 78 & 67.5 & 11.4 & 40 & 100 & \\
\hline stroke & 11 & 69.7 & 15.3 & 55 & 110 & \\
\hline heparin dose & & & & & & 0.704 \\
\hline no stroke & 12 & 2500.8 & 2032.7 & 10 & 7500 & \\
\hline stroke & 3 & 3000 & 1732.1 & 2000 & 5000 & \\
\hline diameter of STA (mm) & & & & & & 0.178 \\
\hline no stroke & 79 & 1.6 & 0.7 & 1 & 4 & \\
\hline stroke & 12 & 1.9 & 0.5 & 1 & 3 & \\
\hline diameter of MCA cortical branch (mm) & & & & & & 0.105 \\
\hline no stroke & 79 & 1.5 & 0.6 & 1 & 3 & \\
\hline stroke & 12 & 1.8 & 0.5 & 1 & 2 & \\
\hline
\end{tabular}

tality and a $3 \%$ perioperative stroke rate were reported in a contemporary study of 73 similar patients. ${ }^{23}$ In the multicenter randomized EC-IC bypass trial, 81 strokes $(12.2 \%)$ in 663 surgical patients occurred between randomization and 30 days postoperatively according to an intent-to-treat analysis of the surgical data. Sixteen of the perioperative strokes occurred in patients randomized to surgery but prior to an STA-MCA bypass procedure. The actual (on-treatment) perioperative stroke rate in this trial was 65 perioperative strokes $(9.9 \%)$ in 652 STA-MCA bypass procedures, including 20 major strokes (3\%), with 4 of these strokes $(0.6 \%)$ having a fatal outcome. ${ }^{3,13}$

There was a substantial occurrence of postoperative nonstroke serious adverse events in the COSS, including 2 patients who also had postoperative stroke and 12 who did not. The rate of postoperative nonstroke serious adverse events in the COSS was similar to those in previously published studies of STA-MCA bypasses. Most reports of morbidities associated with STA-MCA bypass surgery have focused on ischemic neurological deficits and have not listed other nonstroke perioperative morbidity rates. However, a 1978 review of 376 STA-MCA bypass procedures documented a perioperative rate of "other morbidity" (noncerebral ischemic) as $13.6 \% .^{32}$ Seven $(2 \%)$ of 400 patients, ${ }^{7} 12(3 \%)$ of 415 patients, ${ }^{36}$ and $3(6 \%)$ of 47 patients ${ }^{34}$ undergoing STA-MCA bypass had a postoperative subdural hematoma/subdural hygroma requiring surgical drainage or subdural-peritoneal shunting. Scalp necrosis around the skin incision developed in $7 \%{ }^{31}$ and $1.3 \%$ of patients in 2 series of STA-MCA bypasses. 
A pulmonary embolus occurred in $4(6 \%)$ of 70 patients after STA-MCA bypass. ${ }^{31}$

In the EC-IC arterial bypass data submitted prior to the COSS trial, many of the bypass procedures were not STA-MCA bypasses. Some of them were high-flow extracranial carotid artery-MCA anastomoses utilizing a saphenous vein graft or radial artery graft. Many of these self-reported procedures were done in patients undergoing deliberate ICA or MCA occlusion for intracranial aneurysm treatment, intracranial tumor resection, or cerebral ischemia caused by moyamoya disease. Moreover, the majority of patients were younger than those in the COSS. Inexperience with the STA-MCA bypass procedure might account for the higher rate of postoperative stroke in the COSS. However, the surgeons in the COSS who provided the pretrial data had similar results in the COSS. There was no difference in the 30-day postoperative and > 30 days stroke rate between departmental/divisional chairs and the rest of the surgeons in the trial. Furthermore, the 30-day postoperative stroke rate of $15 \%$ in the COSS was not statistically different from the $9.8 \%$ 30-day postoperative stroke rate seen in the EC-IC bypass trial ( $\mathrm{p}=0.136$, chi-square test). An extensive analysis of multiple baseline characteristics and intraoperative variables did not reveal any factors that would definitely identify patients with an increased risk of procedure-related stroke.

\section{Conclusions}

The COSS demonstrated that STA-MCA arterial bypass markedly improved, although it did not normalize, the level of elevated OEF in the symptomatic cerebral hemisphere in patients with symptomatic complete occlusion of the ICA. After the 2nd POD, the rate of recurrent ipsilateral stroke for the remainder of the 2-year followup period was only 9\%. However, despite excellent bypass graft patency and improved cerebral hemodynamics, STA-MCA anastomosis did not provide an overall benefit regarding the 2-year ipsilateral stroke recurrence, mainly because of a much better than expected stroke recurrence rate $(22.7 \%)$ in the medical group in the trial, but also because of a significant postoperative stroke rate of $15 \%$. The study also confirmed that severe impairment of cerebral hemodynamics is an important risk factor for subsequent stroke in patients with symptomatic complete occlusion of the ICA and that PET measurements of OEF are an accurate means of identifying patients with an occluded ICA at high risk for recurrent stroke due to poor collateral circulation. ${ }^{27}$ The findings of the trial reaffirm both the hazard of relying on even the most carefully studied historical controls and the necessity of performing randomized controlled trials to establish clinical efficacy.

\section{Appendix}

Surgeons who performed an STA-MCA bypass in the COSS are as follows: Ali F. Krisht, University of Arkansas, Little Rock, AR; Neil Martin, University of California, Los Angeles, CA; Michael Lawton, University of California, San Francisco, CA; Mario Zuccarello, University of Cincinnati, OH; Peter Rasmussen, Cleveland Clinic, Cleveland, OH; E. Sander Connolly, Columbia
University, New York, NY; Daniel Barrow, Emory University, Atlanta, GA; Terry Horner, Goodman Campbell Brain and Spine, Indianapolis, IN; Fady T. Charbel, University of Illinois, Chicago, IL; Michael B. Pritz, Indiana University, Indianapolis, IN; Patrick Hitchon, University of Iowa, Iowa City, IA; Steven Lownie, London Health Sciences Centre, London, ON, Canada; Douglas Anderson, Loyola University, Chicago, IL; Christopher Ogilvy, Massachusetts General Hospital, Boston, MA; Frederic Meyer, David Piepgras, Mayo Clinic, Rochester, MN; B. Gregory Thompson, University of Michigan, Ann Arbor, MI; James Budny, L. Nelson Hopkins, Millard Fillmore Gates Hospital, Buffalo, NY; Howard Yonas, University of New Mexico, Albuquerque, NM, and University of Pittsburgh, PA; Robert Spetzler, St. Joseph's Hospital and Medical Center, Phoenix, AZ; Gary K. Steinberg, Stanford University, Palo Alto, CA; Jean-Louis Caron, University of Texas Health Sciences Center, San Antonio, TX; Thomas A. Kopitnik, Duke Samson, University of Texas Southwestern Medical Center, Dallas, TX; Robert Rosenwasser, Thomas Jefferson University, Philadelphia, PA; John A. Wilson, Wake Forest University, Winston-Salem, NC; Ralph Dacey, Gregory Zipfel, Washington University in St. Louis, MO; and Robert Dempsey, University of Wisconsin, Madison, WI.

\section{Disclosure}

This research was supported by US Public Health Service (USPHS) Grant Nos. NS39526, NS42157, and NS41895 from the NINDS. The USPHS had no role in the design, collection, management, analysis, or interpretation of the data or in the preparation of the manuscript. A member of the Executive Committee that oversaw the conduct of the trial was appointed by NINDS. A Data, Safety, and Monitoring Board appointed by NINDS oversaw the conduct of the trial and had access to all data.

The opinions expressed are those of the authors and not necessarily those of Washington University in St. Louis, the University of North Carolina-Chapel Hill, or the University of Iowa.

Author contributions to the study and manuscript preparation include the following. Conception and design: all authors. Acquisition of data: all authors. Analysis and interpretation of data: all authors. Drafting the article: Grubb, Powers, Clarke. Critically revising the article: all authors. Reviewed submitted version of manuscript: all authors. Approved the final version of the manuscript on behalf of all authors: Grubb. Statistical analysis: Clarke. Administrative/technical/material support: all authors. Study supervision: Grubb, Powers, Clarke.

\section{References}

1. Adams HP Jr, Bendixen BH, Leira E, Chang KC, Davis PH, Woolson RF, et al: Antithrombotic treatment of ischemic stroke among patients with occlusion or severe stenosis of the internal carotid artery: a report of the Trial of Org 10172 in Acute Stroke Treatment (TOAST). Neurology 53:122-125, 1999

2. Ausman JI, Diaz FG: Critique of the extracranial-intracranial bypass study. Surg Neurol 26:218-221, 1986

3. Barnett HJM, Fox A, Hachinski V, Haynes B, Peerless SJ, Sackett D, et al: Further conclusions from the extracranial-intracranial bypass trial. Surg Neurol 26:227-235, 1986

4. Baron JC, Bousser MG, Rey A, Guillard A, Comar D, Castaigne P: Reversal of focal "misery-perfusion syndrome" by extra-intracranial arterial bypass in hemodynamic cerebral ischemia. A case study with 150 positron emission tomography. Stroke 12:454-459, 1981

5. Brisman JL, Song JK, Newell DW: Cerebral aneurysms. N Engl J Med 355:928-939, 2006

6. Broderick J, Brott T, Kothari R, Miller R, Khoury J, Pancioli A, et al: The Greater Cincinnati/Northern Kentucky Stroke Study: preliminary first-ever and total incidence rates of stroke among blacks. Stroke 29:415-421, 1998 
7. Chater N: Neurosurgical extracranial-intracranial bypass for stroke: with 400 cases. Neurol Res 5:1-9, 1983

8. Day AL, Rhoton AL Jr, Little JR: The extracranial-intracranial bypass study. Surg Neurol 26:222-226, 1986

9. Derdeyn CP, Grubb RL Jr, Powers WJ: Cerebral hemodynamic impairment: methods of measurement and association with stroke risk. Neurology 53:251-259, 1999

10. Derdeyn CP, Videen TO, Simmons NR, Yundt KD, Fritsch SM, Grubb RL Jr, et al: Count-based PET method for predicting ischemic stroke in patients with symptomatic carotid arterial occlusion. Radiology 212:499-506, 1999

11. Donaghy RMP: History of microneurosurgery, in Wilkins RH, Rengachary SS (eds): Neurosurgery, ed 2. New York: McGraw-Hill, 1996, Vol 1, pp 37-42

12. Donaghy RMP: Patch and bypass in microangiomal surgery, in Donaghy RMP, Yaşargil MG (eds): Microvascular Surgery. St. Louis: CV Mosby, 1967, pp 75-86

13. EC/IC Bypass Study Group: Failure of extracranial-intracranial arterial bypass to reduce the risk of ischemic stroke. Results of an international randomized trial. N Engl J Med 313: 1191-1200, 1985

14. Flaherty ML, Flemming KD, McClelland R, Jorgensen NW, Brown RD Jr: Population-based study of symptomatic internal carotid artery occlusion: incidence and long-term followup. Stroke 35:e349-e352, 2004

15. Gibbs JM, Wise RJ, Thomas DJ, Mansfield AO, Russell RW: Cerebral haemodynamic changes after extracranial-intracranial bypass surgery. J Neurol Neurosurg Psychiatry 50: 140-150, 1987

16. Grubb RL Jr, Derdeyn CP, Fritsch SM, Carpenter DA, Yundt $\mathrm{KD}$, Videen TO, et al: Importance of hemodynamic factors in the prognosis of symptomatic carotid occlusion. JAMA 280: 1055-1060, 1998

17. Grubb RL Jr, Ratcheson RA, Raichle ME, Kliefoth AB, Gado $\mathrm{MH}$ : Regional cerebral flow and oxygen utilization in superficial temporal-middle cerebral artery anastomosis patients: an exploratory definition of clinical problems. J Neurosurg 50:733-741, 1979

18. Hankey GJ, Warlow CP: Prognosis of symptomatic carotid artery occlusion. Cerebrovasc Dis 1: 245-256, 1991

19. Jack CR Jr, Sundt TM Jr, Fode NC, Gehring DG: Superficial temporal-middle cerebral artery bypass: clinical pre- and postoperative angiographic correlation. J Neurosurg 69:4651,1988

20. Klijn CJM, Kappelle LJ, Tulleken CAF, van Gijn J: Symptomatic carotid artery occlusion. A reappraisal of hemodynamic factors. Stroke 28:2084-2093, 1997

21. Klijn CJM, van Buren PA, Kappelle LJ, Tulleken CAF, Eikelboom BC, Algra A, et al: Outcome in patients with symptomatic occlusion of the internal carotid artery. Eur J Vasc Endovasc Surg 19:579-586, 2000

22. Mead GE, Murray H, Farrell A, O'Neill PA, McCollum CN: Pilot study of carotid surgery for acute stroke. Br J Surg 84: 990-992, 1997

23. Mendelowitsch A, Taussky P, Rem JA, Gratzl O: Clinical outcome of standard extracranial-intracranial bypass surgery in patients with symptomatic atherosclerotic occlusion of the internal carotid artery. Acta Neurochir (Wien) 146:95-101, 2004

24. Ogasawara K, Ogawa A, Yoshimoto T: Cerebrovascular reactivity to acetazolamide and outcome in patients with symptomatic internal carotid or middle cerebral artery occlusion: a xenon-133 single-photon emission computed tomography study. Stroke 33:1857-1862, 2002

25. Peerless SJ, Gamache FW Jr, Hunter IG: Continuous suture method for microvascular anastomosis: technical note. Neurosurgery 8:695-698, 1981

26. Pessin MS, Duncan GW, Mohr JP, Poskanzer DC: Clinical and angiographic features of carotid transient ischemic attacks. N Engl J Med 296:358-362, 1977
27. Powers WJ, Clarke WR, Grubb RL Jr, Videen TO, Adams HP Jr, Derdeyn CP: Extracranial-intracranial bypass surgery for stroke prevention in hemodynamic cerebral ischemia: the Carotid Occlusion Surgery Study randomized trial. JAMA 306:1983-1992, 2011 (Erratum in JAMA 306:2672, 2011)

28. Powers WJ, Grubb RL Jr, Raichle ME: Clinical results of extracranial-intracranial bypass surgery in patients with hemodynamic cerebrovascular disease. J Neurosurg 70:61-67, 1989

29. Powers WJ, Martin WRW, Herscovitch P, Raichle ME, Grubb RL Jr: Extracranial-intracranial bypass surgery: hemodynamic and metabolic effects. Neurology 34:1168-1174, 1984

30. Ratcheson RA, Grubb RL Jr: Superficial temporal-middle cerebral cortical artery anastomosis, in Smith RR (ed): Stroke and the Extracranial Vessels. New York: Raven Press, 1984, pp 255-263

31. Reichman $\mathrm{OH}$ : Complications of cerebral revascularization. Clin Neurosurg 23:318-335, 1976

32. Samson DS, Boone S: Extracranial-intracranial (EC-IC) arterial bypass: past performance and current concepts. Neurosurgery 3:79-86, 1978

33. Samson Y, Baron JC, Bousser MG, Rey A, Derlon JM, David $\mathrm{P}$, et al: Effects of extra-intracranial arterial bypass on cerebral blood flow and oxygen metabolism in humans. Stroke 16: 609-616, 1985

34. Schick U, Zimmermann M, Stolke D: Long-term evaluation of EC-IC bypass patency. Acta Neurochir (Wien) 138:938-943, 1996

35. Sundt TM Jr: Was the international randomized trial of extracranial-intracranial arterial bypass representative of the population at risk? N Engl J Med 316:814-816, 1987

36. Sundt TM Jr, Whisnant JP, Fode NC, Piepgras DG, Houser OW: Results, complications, and follow-up of 415 bypass operations for occlusive disease of the carotid system. Mayo Clin Proc 60:230-240, 1985

37. Thiele BL, Young JV, Chikos PM, Hirsch JH, Strandness DE $\mathrm{Jr}$ : Correlation of arteriographic findings and symptoms in cerebrovascular disease. Neurology 30:1041-1046, 1980

38. Vilela MD, Newell DW: Superficial temporal artery to middle cerebral artery bypass: past, present, and future. Neurosurg Focus 24(2):E2, 2008

39. Williams GR, Jiang JG, Matchar DB, Samsa GP: Incidence and occurrence of total (first-ever and recurrent) stroke. Stroke 30:2523-2528, 1999

40. Yamauchi H, Fukuyama H, Nagahama Y, Nabatame H, Ueno M, Nishizawa S, et al: Significance of increased oxygen extraction fraction in five-year prognosis of major cerebral arterial occlusive diseases. J Nucl Med 40:1992-1998, 1999

41. Yaşargil MG (ed): Anastomosis between the superficial temporal artery and a branch of the middle cerebral artery, in: Microsurgery Applied to Neurosurgery. Stuttgart: George Thieme Verlag, 1969, pp 105-115

42. Zumstein B, Yaşargil MG: [Improvement of cerebral blood circulation by microsurgical bypass-anastomoses (author's transl).] Schweiz Rundsch Med Prax 70:1866-1873, 1981 (Ger)

Manuscript submitted March 20, 2012.

Accepted September 26, 2012.

Portions of this work were presented as an oral presentation during Plenary Session I at the AANS 2011 Annual Meeting held in Denver, Colorado, on April 9-13, 2011.

Please include this information when citing this paper: published online October 26, 2012; DOI: 10.3171/2012.9.JNS12551.

Address correspondence to: Robert L. Grubb Jr., M.D., Box 8057, Department of Neurological Surgery, Washington University Medical Center, 660 South Euclid Avenue, St. Louis, Missouri 63110. email: grubbro@wudosis.wustl.edu. 